\title{
Studi Pendahuluan Sintesis Metil Ester Sulfonat dari Tanaman Jarak Pagar Menggunakan Katalis Hidrotalsit
}

\author{
Nurmaya Arofah $1^{(1, a) *}$ dan Eka Larasanti $2^{(2)}$ \\ ${ }^{(1)}$ Program Studi Teknik Pertambangan Fakultas Sains dan Teknologi UIN Syarif Hidayatullah, Tangerang \\ Selatan Indonesia, 15412 \\ ${ }^{(2)}$ Alumni Program Studi Kimia Fakultas Sains dan Teknologi UIN Syarif Hidayatullah, Tangerang Selatan \\ Indonesia, 15412 \\ Email: ${ }^{\left(a^{*}\right)}$ nurmayaarofah@uinjkt.ac.id
}

Diterima (12 November 2021), Direvisi (31 Desember 2021)

\begin{abstract}
A preliminary study research on the synthesis of surfactant methyl ester sulfonate (MES) from methyl ester (ME) of castor oil transesterified with hydrotalcite catalysts has been carried out. This study aims to determine the characteristics of the hydrotalcite MgAl-CO3 catalyst used in the synthesis of MES from jatropha oil, determine the identification of ME and MES functional groups by FTIR spectrophotometry and the resulting HLB MES values. The method of this research is transesterification reaction using alkaline hydrotalcite $\mathrm{MgAlCO}_{3}$ catalyst and sulfonation using sodium bisulfite. The results of identification of functional groups on MES with a FT-IR spectrophotometer were produced in the presence of sulfonate groups shown in the FTIR spectra at a wave number of about 1107,94 $\mathrm{cm}^{-1}$. In addition, the HLB MES value is -1.6343.
\end{abstract}

Keywords : catalyst, hidrotalsit, methyl ester sulfonate

Abstrak: Telah dilakukan penelitian studi pendahuluan sintesis surfaktan metil ester sulfonat (MES) dari metil ester (ME) minyak jarak pagar hasil transesterifikasi dengan katalis hidrotalsit. Penelitian ini bertujuan untuk menentukan karakteristik dari katalis hidrotalsit $\mathrm{MgAl}-\mathrm{CO}_{3}$ yang digunakan dalam sintesis MES, mengidentifikasi gugus fungsi MES dengan spektrofotometri FTIR serta menentukan nilai HLB MES yang dihasilkan. Metode penelitian ini dengan cara reaksi transesterifikasi menggunakan katalis basa hidrotalsit $\mathrm{MgAlCO} 3$ dan sulfonasi menggunakan natrium bisulfit. Hasil identifikasi gugus fungsi pada MES dengan FT-IR dihasilkan adanya gugus sulfonat yang ditunjukkan dalam spektrum FTIR pada bilangan gelombang 1107,94 $\mathrm{cm}^{-1}$ dan nilai HLB MES sebesar -1,6343.

Kata kunci : katalis, hidrotalsit, methyl ester sulfonate

\section{PENDAHULUAN}

Metode yang digunakan untuk mengoptimalkan perolehan minyak bumi, Salah satunya adalah metode chemical flooding menggunakan surfaktan [1]. Surfaktan adalah senyawa aktif yang memiliki sifat amfifilik yang mengandung gugus hidrofilik (bagian kepala) dan hidrofobik (bagian ekor). Surfaktan memiliki kemampuan untuk menurunkan tegangan permukaan, dan juga dapat meningkatkan kestabilan dari partikel [2].
Surfaktan biasanya berbahan baku minyak bumi, namun dampak negatif seperti menimbulkan masalah lingkungan jika sering digunakan, dapat membentuk fenol yang bersifat racun/toksik bagi biota di perairan [3]. Oleh karena itu, diperlukan alternatif surfaktan dari bahan baku minyak nabati yang bersifat non toxic dan lebih ramah lingkungan.

Metil Ester Sulfonat atau MES termasuk jenis surfaktan anionik berbahan baku minyak nabati, mengandung asam lemak rantai $\mathrm{C}_{16}-\mathrm{C}_{18}$ yang bersifat biodegradable [4]. MES dapat dihasilkan dari bahan baku proses esterifikasi 
dan transesterifikasi yaitu Metil Ester (ME). Sintesis MES berbahan baku ME dari minyak kelapa sawit telah dilakukan $^{[4]}$, akan tetapi penggunaan minyak nabati dari kelapa sawit sebagai bahan baku ME memiliki daya saing dengan komoditas pangan. Minyak jarak pagar (Jatropa Curcas L) merupakan salah satu bahan baku alternatif yang memiliki potensial dan belum banyak dimanfaatkan untuk bahan baku surfaktan anionik. Keunggulan menggunakan minyak jarak sebagai bahan baku MES adalah tidak memiliki daya saing dengan produk pangan, karena minyak jarak pagar mengandung racun seperti phorbol ester dan curcin, mudah dibudidayakan, lebih murah dibanding minyak sawit, kedelai dan minyak nabati lainnya yang dikonsumsi [5].

Metil Ester dari bahan baku minyak jarak pagar kemudian direaksikan dengan agen pensulfonasi, seperti natrium bisulfit [16]. Penggunaan $\mathrm{NaHSO}_{3}$ memiliki keunggulan dapat menghasilkan warna produk MES lebih cerah dan mudah untuk diaplikasikan pada skala produk kecil [4].

Reaksi sulfonasi membutuhkan waktu yang lama, sehingga diperlukan suatu katalis agar dapat mempercepat reaksi. Salah satu katalis yang dapat digunakan adalah hidrotalsit. Hidrotalsit adalah salah satu mineral yang prospektif, karena dapat berguna dalam berbagai aplikasi salah satunya sebagai katalis basa yang dapat digunakan untuk reaksi sulfonasi [6]. Katalis yang dapat digunakan untuk sulfonasi adalah $\mathrm{CuO}$, namun menghasilkan produk akhir MES berwarna hitam sehingga diperlukan proses bleaching. Katalis $\mathrm{V}_{2} \mathrm{O}_{5}$ juga dapat digunakan sebagai katalis reaksi sulfonasi, namun harga katalis tersebut relatif mahal [7]. Pada penelitian ini digunakan Hidrotalsit $\mathrm{MgAlCO}_{3}$ untuk reaksi sulfonasi MES dari ME.

Berdasarkan hal di atas maka perlu dilakukan studi pendahuluan untuk mengetahui sintesis MES dari bahan baku
ME dengan katalis hidrotalsit, mengidentifikasi gugus fungsi MES hasil sintesis dan menentukan nilai HLB untuk mengetahui jenis surfaktan.

\section{METODE PENELITIAN}

Prosedur kerja pada penelitian ini dapat dilihat pada Gambar 1 dan 2 di bawah ini:

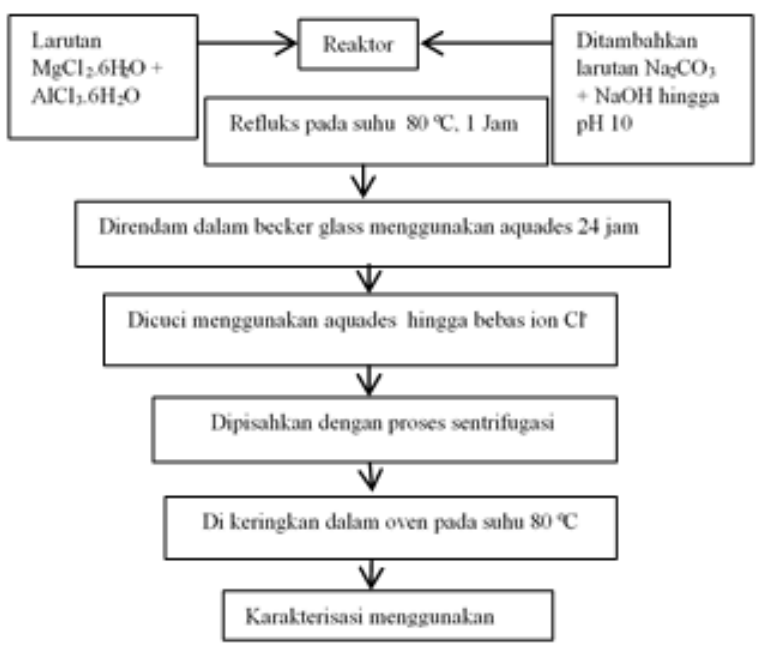

Gambar 1. Diagram Alir Sintesis Hidrotalsit

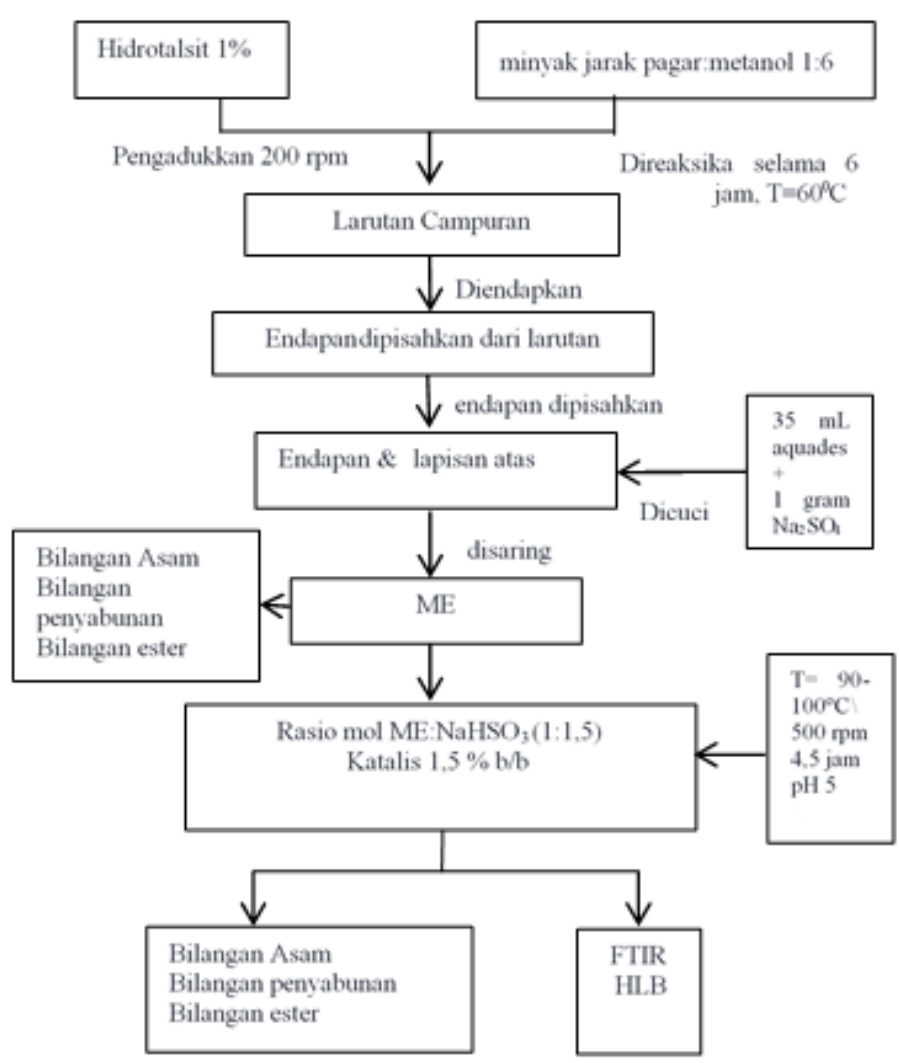

Gambar 2. Diagram Alir Sintesis MES 


\section{Penentuan Bilangan Asam ME}

Sebanyak 1 gram ME ditimbang, ditambahkan metanol netral 96\% sebanyak $5 \mathrm{~mL}$, dipanaskan selama 10 menit menggunakan penangas air, kemudian diaduk-aduk agar tercampur. Sample dititrasi dengan $\mathrm{KOH} 0,1 \mathrm{~N}$ menggunakan indikator fenolftalein (PP) sebanyak 1-3 tetes, sampai terlihat warna merah jambu. Selanjutnya ditentukan bilangan asam menggunakan Persamaan 1 berikut ini.

$$
A v=\frac{(\text { sampel-blanko }) \times N K O H \times 56.1}{\text { Gram sampel }}
$$

\section{Penentuan bilangan penyabunan ME}

Sebanyak 1 gram ME ditimbang, kemudian ditambahkan larutan $\mathrm{KOH}$ alkoholis sebanyak $10 \mathrm{~mL}$ dan direfluks. Sample ditambahkan indikator PP sebanyak 1-3 tetes, selanjutnya dititrasi menggunakan $\mathrm{HCl} \quad 0,5 \mathrm{~N}$, dihitung bilangan penyabunan menggunakan

\section{Penentuan bilangan ester}

Penentuan bilangan ester dihasilkan dari selisih antara bilangan penyabunan dan bilangan asam yang sudah ditentukan sebelumnya.

Nilai HLB ME hasil sintesis dihitung menggunakan Persamaan 2.

$$
H L B=20 \times\left(1-\frac{S}{A}\right)
$$

dimana $S$ adalah bilangan penyabunan sampel dan A adalah bilangan asam Fatty Acid.

\section{HASIL DAN PEMBAHASAN}

\section{Sintesis Hidrotalsit}

Hidrotalsit $\mathrm{Mg}-\mathrm{Al}-\mathrm{CO}_{3} \quad$ yang digunakan sebagai katalis disintesis melalui metode kopresipitasi dengan rasio mol $\mathrm{Mg} / \mathrm{Al}$ 1,7:1[8]. Sintesis hidrotalsit dilakukan dengan mereaksikan larutan
$\mathrm{MgCl}_{2} \cdot 6 \mathrm{H}_{2} \mathrm{O} 0,63 \mathrm{M}$ dan $\mathrm{AlCl}_{3} \cdot 6 \mathrm{H}_{2} \mathrm{O} 0,37 \mathrm{M}$ sebagai larutan $\mathrm{A}$ dengan larutan $\mathrm{Na}_{2} \mathrm{CO}_{3} 0,63$ $\mathrm{M}$ dalam suasana basa (dengan penambahan larutan $\mathrm{NaOH}$ 2,2 M) sebagai larutan $\mathrm{B}$. Larutan garam yang terbentuk dijenuhkan dengan tambahan larutan alkali hingga pHnya mencapai $\mathrm{pH}$ optimum sintesis yaitu 10. Untuk menghasilkan hidrotalsit yang memiliki kristalinitas dan kemurnian yang tinggi, sangat penting mengkondisikan $\mathrm{pH}$ larutan sebagai $\mathrm{pH}$ basa selama berlangsungnya sintesis. Kemudian larutan alkali tersebut ditambahkan ke dalam larutan garam yang sudah dibuat secara simultan untuk mendorong terjadinya pengendapan, hal ini dilakukan bersamaan dengan proses pengadukan. Selanjutnya dilakukan refluks pada suhu $80{ }^{\circ} \mathrm{C}$ selama 1 jam [9][15].

Hidrotalsit $\mathrm{Mg}-\mathrm{Al}-\mathrm{CO}_{3}$ hasil sintesis dikarakterisasi dengan XRD untuk menentukan kristalinitas, tujuannya adalah untuk mengidentifikasi fasa kristalin hidrotalsit $\mathrm{Mg}$ $\mathrm{Al}-\mathrm{CO}_{3}$ hasil sintesis, dengan mengetahui nilai $d$-spacing, karena setiap kristal memiliki nilai $d$-spacing yang khas. Nilai $d$-spacing pada puncak-puncak difraktogram hidrotalsit $\mathrm{Mg}$ $\mathrm{Al}-\mathrm{CO}_{3}$ hasil sintesis dibandingkan dengan standar dari International Centre for Diffraction Data (ICDD). Difraktogram hidrotalsit hasil sintesis yang dapat dilihat pada Gambar 3.

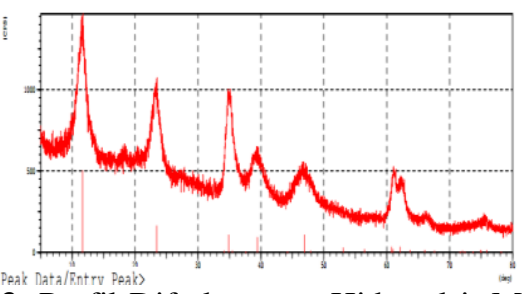

Gambar 3. Profil Difraktogram Hidrotalsit $\mathrm{Mg}-\mathrm{Al}-\mathrm{CO}_{3}$ Hasil Sintesis

Difraktogram hasil analisis dibandingkan dengan referensi ICDD. Pola difraktogram pada Gambar 1 di atas memiliki kemiripan dengan pola difraktogram hidrotalsit $\mathrm{Mg}-\mathrm{Al}-$ $\mathrm{CO}_{3}$ yang telah dilaporkan [10] dapat dilihat pada Gambar 4 bahwa puncak puncak tersebut merupakan difraktogram khas yang dimiliki oleh hidrotalsit $\mathrm{Mg}-\mathrm{Al}-\mathrm{CO}_{3}$. 


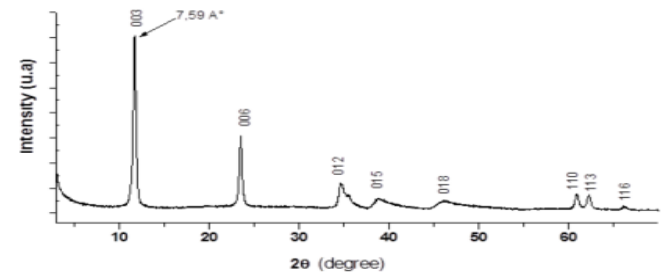

Gambar 4. Profil Difraktogram Hidrotalsit Mg-Al$\mathrm{CO}_{3}$ XRD dari Referensi Jurnal [10].

Berdasarkan data ICDD, Anion $\mathrm{CO}_{3}{ }^{2-}$ antar lapisan hidrotalsit $\mathrm{Mg}-\mathrm{Al}-\mathrm{CO}_{3}$ ditunjukkan dengan nilai $d_{003}=7,599 \AA$ yang muncul pada $2 \theta 11,635^{\circ}$. Nilai tersebut sesuai dengan nilai $d_{003}$ yang diperoleh [10] yaitu fasa kristal hidrotalsit dengan anion $\mathrm{CO}_{3}^{2-}$ ditunjukkan dengan nilai $d_{003}$ adalah $7,59 \AA$ A. Berdasarkan perbandingan dengan referensi tersebut dapat disimpulkan bahwa senyawa hidrotalsit $\mathrm{Mg}-\mathrm{Al}-\mathrm{CO}_{3}$ yang telah disintesis telah terbentuk.

\section{Reaksi Transesterifikasi}

Sintesis ME merupakan tahapan utama dalam sintesis MES, MES dapat disintesis melalui beberapa tahap yaitu transesterifikasi, sulfonasi dan pengendapan. Hasil reaksi transesterifikasi pada penelitian ini merupakan cairan berwarna kuning yang mengandung $\mathrm{ME}$ dan gliserol. MES yang dihasilkan dipisahkan menggunakan metode ekstraksi cair-cair dengan tambahan aquades. Hasil pemisahan membentuk dua lapisan, dimana lapisan atas merupakan ME yang berwarna kuning sedangkan lapisan bawah merupakan gliserol yang berwarna putih, akuades, sisa metanol dan sisa kalium hidroksida. Terbentuknya lapisan tersebut dikarenakan ME memiliki sifat non polar dan gliserol bersifat polar. Penambahan $\mathrm{Na}_{2} \mathrm{SO}_{4}$ anhidrat pada ME untuk mengikat air, hasil perhitungan diperoleh $\mathrm{ME}$ sebesar sebanyak 138,7972 gram, dari hasil transesterifikasi minyak jarak sebanyak $100 \mathrm{~mL}$.

Untuk mengetahui $\mathrm{KOH}$ yang digunakan untuk menetralkan asam lemak bebas, dilakukan perhitungan bilangan asam. Untuk mengetahui jumlah asam lemak bebas yang terdapat dalam minyak dengan cara menentukan bilangan asam. Pada penelitian ini, bilangan asam ditentukan menggunakan metode titrasi dengan larutan standar $\mathrm{KOH}$ menggunakan indikator PP [11].

Semakin besar nilai nilai bilangan asam, maka semakin banyak pula penggunaan $\mathrm{KOH}$ yang digunakan pada titrasi untuk menetralkan asam lemak bebas, hal tersebut menunjukkan bahwa semakin banyak asam lemak bebas yang terdapat di dalam minyak. Hasil perhitungan diperoleh bilangan asam minyak jarak sebesar 6,045 $\mathrm{mg} \mathrm{KOH/gram} \mathrm{dan} \mathrm{bilangan} \mathrm{asam} \mathrm{ME}$ sebesar 0,429 mg KOH/gram. Bilangan asam ME hasil perhitungan nilainya lebih rendah jika dibandingkan dengan nilai bilangan asam minyak jarak pagar, hal tersebut dikarenakan asam lemak yang terkandung dalam minyak jarak pagar sudah terkonversi menjadi $\mathrm{ME}$ pada reaksi esterifikasi minyak jarak pagar.

Hasil analisis bilangan penyabunan minyak jarak pagar dan metil ester berturutturut diperoleh sebesar 448,76 mg KOH/gram dan 498,84 mg KOH/gram. Hasil tersebut menunjukkan bahwa sejumlah trigliserida dan asam lemak bebas pada minyak jarak pagar dan metil ester telah tersabunkan oleh $\mathrm{KOH}$ berlebih yang terlarut dalam alkohol. Sabun yang terbentuk pada reaksi merupakan garam alkali karboksilat yang berasal dari rantai asam lemak dan gliserida yang terdapat dalam minyak jarak pagar maupun ME. Semakin banyak sabun yang terbentuk, semakin kecil bobot molekul asam lemak dan gliserida yang terkandung dalam minyak minyak jarak pagar dan ME [12].

Bilangan ester minyak jarak pagar dan $\mathrm{ME}$ hasil penelitian adalah 442,715 mg KOH/gram dan 498,41 mg KOH/gram. Nilai bilangan ester dari ME tersebut lebih besar jika dibandingkan dengan nilai bilangan ester minyak jarak. Menurut $^{[12]}$, dalam penelitiannya menjelaskan bahwa Asam lemak bebas yang terkandung di dalam minyak jarak dapat bereaksi saat proses transesterifikasi menjadi senyawa ME sehingga bilangan ester ME lebih besar dari bilangan ester minyak jarak pagar. 


\section{Reaksi Sulfonasi}

Produk MES yang dihasilkan dari reaksi sulfonasi adalah merupakan reaksi antara ME dengan agen sulfonasi $\mathrm{NaHSO}_{3}$. Pembentukan gugus sulfonat pada metil ester dapat dimaksimalkan jika menambahkan agen sulfonasi Natrium bisulfit secara berlebih ${ }^{[12]}$ Metil ester sulfonat yang dihasilkan dari proses sulfonasi selanjutnya didiamkan selama 24 jam untuk memisahkannya dengan sisa $\mathrm{NaHSO}_{3}$.

MES yang dihasilkan berwujud cari berwarna kuning cerah bagian atas, dan terdapat sedikit endapan warna putih di bagian bawah, hal tersebut diduga pada produk masih terdapat sisa atau hasil samping reaksi seperti dinatrium karboksi sulfonat katalis hidrotalsit, sisa $\mathrm{NaHSO}_{3}$ dan pengotor lainnya [17]. pH MES yang dihasilkan pada penelitian ini adalah $\mathrm{pH} 5$, $\mathrm{pH}$ ini terlalu rendah atau bersifat asam. Nilai $\mathrm{pH}$ yang terlalu rendah dapat mengakibatkan reaksi hidrolisis pada MES yang dapat membentuk pengotor berupa di-salt dan metanol [12]. Oleh karena itu perlu dilakukan penetralan untuk meningkatkan nilai $\mathrm{pH}$ menjadi netral, sedangkan pada penelitian ini belum dilakukan tahapan pemurnian dan akan dilanjutkan pada tahapan penelitian selanjutnya. Rendemen yang diperoleh dari hasil penelitian MES dihasilkan sebanyak 18,615 gram.

Hasil identifikasi gugus sulfonat pada MES menggunakan FTIR dapat dilihat pada Gambar 3 di bawah ini.

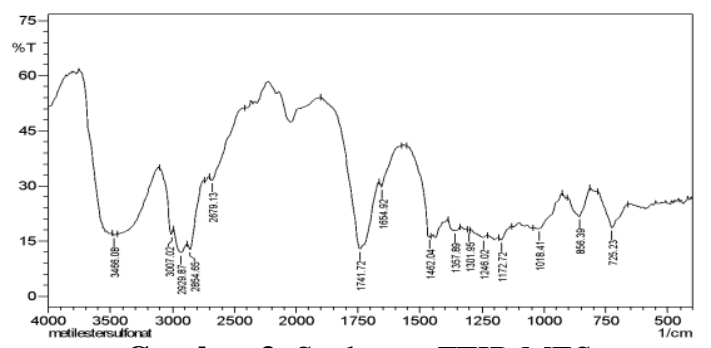

Gambar 3. Spektrum FTIR MES

Puncak serapan gugus sulfonat hasil identifikasi ditunjukkan pada panjang gelombang 1107,94 $\mathrm{cm}^{-1}$ seperti pada Gambar 3. Hasil penelitian [13], menjelaskan bahwa pembentukan gugus sulfonat diperlihatkan pada bilangan gelombang 1235 sampai 1172 $\mathrm{cm}^{-1}$. MES yang diperoleh hasil reaksi ME dari Methyl Soyate dan $\mathrm{NaHSO}_{3}$ dengan rasio mol rasio 1:1 dalam suhu $100{ }^{\circ} \mathrm{C}$, menunjukkan adanya puncak serapan gugus sulfonat pada panjang gelombang $1362 \mathrm{~cm}^{-1}$ hingga $1026 \mathrm{~cm}^{-}$ 1. Perbedaan bilangan gelombang dapat diakibatkan faktor vibrasi [4].

Nilai HLB dari MES dihitung untuk mengetahui apakah MES hasil sintesis termasuk ke dalam surfaktan anionik. Berdasarkan hasil perhitungan nilai HLB menggunakan metode titrasi diperoleh sebesar $-1,6343$ hal tersebut menunjukkan bahwa hasil yang diperoleh tidak tergolong surfaktan anionik [14]. Oleh karena itu MES hasil sintesis belum bisa digunakan sebagai chemical flooding pada perolehan minyak bumi. Hal ini disebabkan karena MES masih banyak mengandung pengotor, maka perlu dilakukan pemurnian. Selain itu metode titrasi untuk penentuan nilai HLB memiliki error yang besar maka perlu dibandingkan dengan instrumen GPC.

\section{KESIMPULAN}

Rasio mol ME: $\mathrm{NaHSO}_{3}(1: 1,5)$ dan katalis $1,5 \%$ b/b menghasilkan MES sebanyak 18,615 gram, hidrotalsit memiliki potensi untuk digunakan sebagai katalis pada reaksi sulfonasi, hasil identifikasi puncak serapan gugus sulfonat menggunakan FTIR berada pada panjang gelombang gelombang 1107,94 $\mathrm{cm}^{-1}$ dan nilai HLB menggunakan metode titrasi diperoleh sebesar -1,6343, sehingga surfaktan MES belum dapat diaplikasikan.

\section{UCAPAN TERIMA KASIH}

Penulis menyampaikan ucapan terima kasih kepada Pusat Penelitian dan Penerbitan (PUSLITPEN) Lembaga Penelitian dan Pengabdian Masyarakat UIN Syarif Hidayatullah Jakarta yang telah mendanai penelitian ini. 


\section{Nurmaya Arofah : Studi Pendahuluan Sintesis Metil Ester Sulfonat dari Tanaman Jarak Pagar Menggunakan Katalis Hidrotalsit \\ Jurnal Migasian, e-issn: 2615-6695 / p-issn: 2580-5258}

\section{DAFTAR PUSTAKA}

[1] Juita R, Arnelli, Yusniati, 2016, Telaah Surfaktan untuk Proses Enhanced Oil Recovery (EOR) dan Profil Adsorpsi Surfaktan A-Olefin Sulfonates (AOS), Jurnal Kimia Sains dan Aplikasi 19 (1) (2016) : 27-31.

[2] Reningtyas, R, Mahreni, 2015, Biosurfaktan, Eksergi, Vol XII, No. 2, Hal. 12-22.

[3] Utomo, R. N., 2010, Potensi Bakteri Pembentuk Biofilm dalam Mendegradasi Liniar Alkilbenzene Sulfonat pada berbagai Ukuran Batu, Skripsi, FMIPA Universitas Brawijaya, Malang.

[4] Putra, R., Adi, Renisa Ismayanti dan Agam Duma Kalista W, 2018, Sintesis Metil Ester Sulfonat Melalui Sulfonasi Metil Ester Minyak Kedelai untuk aplikasi chemical flooding.Jurnal sains materi indonesia vol. 19, No. 2, hal. 77-8.

[5] Priyanto, U. (2007). "Pemanfaatan Bio Fuel Sebagai Bahan Bakar Alternatif'. Seminar Nasional, Menyikapi Krisis Energi dan Perkembangan Energi Alternatif di Indonesia, HMTG Universitas Gadjah Mada, Yogyakarta.

[6] Hanzel, S. dan Heather, B. (2006), "Hydrotalcites", MEI Chemical, Manchester M27 8 LS, England.

[7] Smith, J. M. 1981. Chemical Engineering Kinetics. 3rd Edition. McGraw-Hill International Book Company, Kosaido Printing Co., LTD. Tokyo, Japan.
[8] Sharma U, Tyagi B, Jasra RV. 2008. Synthesis and Characterization of $\mathrm{Mg}$ Al-CO3 Layered Double Hydroxide for $\mathrm{CO}_{2}$ Adsorption. Industrial and Engineering Chemistry Research. 47(23): 9588-9595.

[9] Kameda, T. Oshioka, T.Uchida, M. Okuwaki, A. 2010, Synthesis of Hydrotalcite from Seawater and ItsApplication to Phosphorus Removal. Phosphorus, Sulfur and Silicon, Vol. 177:1503-1506.

[10] Bouraada M, Hassiba B, Louis CM. 2014. Removal of Evans Blue and Yellow Thiazole Dyes from Aqueous Solution by $\mathrm{Mg}-\mathrm{Al}-\mathrm{CO}_{3}$ Layeed Double Hydroxides as Anion-exchanger. Mediterranean Journal of Chemistry. 3(3):894-906.

[11] Mappiratu. 2004. Lipida Pangan: Kimia, Biokimia dan Bioteknologi. Palu: Tadulako University Press.

[12] Chasani, M. Nursalim, V.H. Widyaningsih, S. Budiasih. I. N, Kurniawan, W. A. 2014.Synthesis, Purification and Characterization Methyl Ester Sulphonate as Core Material Detergent from Seed Oil of Calophyllum inophyllum L. Molekul, Vol. 9. No. 1. Mei, 2014: 63 - 72

[13] Hidayati S. 2009. Pengaruh Rasio Mol, Suhu dan Lama Reaksi terhadap Tegangan Permukaan dan Stabilitas Emulsi Metil Ester Sulfonat dari CPO. Jurnal Teknologi Industri dan Hasil Pertanian. 14 (1): 38-44.

[14] Tong Z., Shichi, T. And Takagi, K., 2003, Oxidation Catalysis of a Manganese (III) Porphyrin Intercalated in Layered Double Hydroxide Clays,Mater Lett, 57:2258-2261.

[15] Cavani, F., Trifiro, F., and Vaccari, A., 1991, Hydrotalcite-Type Anionic Clays 
Preparation, Properties and Applications, Catalysis Today, 11, 173-301.

[16] Iman, N., Abdul R, R., Nurhaeni., 2016, Sintesis Surfaktan Metil Ester Sulfonat (MES) Dari Metil Laurat, KOVALEN Jurnal Riset Kimia, 2(2): 54-66.

[17] MacArthur, B.W., B Brooks, W.B. Sheats dan N.C. Foster. 2002. Meeting The Challenge of Methylester Sulfonation. The Chemiton Corporation. http://www.chemithon.com/papers_broc hures/Meeting_the_Challenge.doc.

pdf. 